\title{
TERRITÓRIOS PESQUEIROS NA BAÍA DE TODOS OS SANTOS:
}

\author{
disputas, desafios e perspectivas de sua regularização
}

\section{TERRITORIOS DE PESCA EN LA BAÍA DE TODOS OS SANTOS: disputas, desafíos y perspectivas de su regularización}

\author{
Kássia Aguiar Norberto Rios \\ Universidade Federal do Recôncavo da Bahia, Feira de Santana, BA, Brasil \\ kassiarios@ufrb.edu.br
}

\section{Resumo}

O presente artigo tem por objetivo apresentar uma análise das especificidades que envolvem as disputas territoriais presentes nas comunidades tradicionais pesqueiras da Baía de Todos os Santos (BTS) e, a partir disso, os desafios e perspectivas que envolvem a regularização de seus territórios. A BTS, considerada a segunda maior baía do Brasil, possui atualmente, cerca de 241 comunidades pesqueiras identificadas e mais de 72.949 mil pescadores artesanais que sobrevivem diretamente da pesca e da mariscagem. Todavia, o que se observa é que os ambientes que constituem a BTS - os mesmos utilizados pelas comunidades pesqueiras - têm sido gradativamente ocupados, privatizados, contaminados etc. Daí o surgimento das disputas territoriais e, também, a necessidade da regularização do território tradicional local. Metodologicamente, buscamos, através da realização de levantamentos bibliográficos, estatísticos, cartográficos e da realização de pesquisa de campo, construir um banco de dados que nos permitiu identificar e analisar as principais especificidades que envolvem as comunidades pesqueiras do litoral baiano na BTS; assim como espacializar através de tabelas e mapas temáticos a distribuição dessas comunidades e as principais disputas territoriais vivenciadas. Tais etapas nos levaram a pensar os desafios e perspectivas que envolvem a regularização dos territórios pesqueiros na BTS.

Palavras-chave: Territórios pesqueiros. Disputas. Regularização.

\section{Resumen}

El objetivo del presente artículo es presentar un análisis de las especificidades que afectan a las disputas territoriales presentes en las comunidades tradicionales pesqueras de la Baia de Todos os Santos (BTS) y, a partir de esto, los desafíos y perspectivas que implican la regularización de sus territorios. La BTS considerada la segunda mayor bahía de Brasil, tiene actualmente, cerca de 241 comunidades pesqueras identificadas y más de 72.949 mil pescadores artesanales que sobreviven de la pesca y el marisco. Sin embargo lo que se observa es que los ambientes que constituyen la BTS - los mismos utilizados por las comunidades pesquerías - han sido gradualmente ocupados, privatizados, contaminados, etc. De ahí el surgimiento de las disputas territoriales y, también, la necesidad de la regularización del territorio tradicional local. Metodologicamente, buscamos a través de la realización de encuestas bibliográficas, estadísticas, cartográficos y de la realización 
de investigación de campo, construir una base de datos que nos ha permitido identificar y analizar las principales especificidades que implican a las comunidades pesqueras del litoral de baiano en BTS; así como espacializar a través de tablas y mapas temáticos la distribución de estas comunidades y las principales disputas territoriales vivenciadas. Tales etapas nos han llevado a pensar en los desafíos y perspectivas que implican la regularización de los territorios pesqueros en el litoral de Bahia. Tales etapas nos han llevado a pensar en los desafíos y perspectivas que implican la regularización de los territorios pesqueros en el BTS.

Palabras-clave: Territorios pesqueros. Disputes. Regularización.

\section{Introdução}

A Baía de Todos os Santos (BTS) considerada a segunda maior baía do Brasil, possui uma área superior a 1,1 mil km² e um perímetro de $200 \mathrm{~km}$. Atualmente, existem no local cerca de 241 comunidades tradicionais pesqueiras identificadas e mais de 70 mil famílias que têm na pesca a sua principal e, muitas vezes única, fonte de renda (PESQUISA DE CAMPO, 2017). A pesca e a mariscagem representam atividades de subsistência que são desenvolvidas com "o objetivo de prover a alimentação das famílias, que obtém rendimento da venda do excedente e/ou de pescados mais nobres" (SOARES et al., 2009, p.162).

Conhecida como "Quirimurê pelos Tupinambás, a Baía de Todos os Santos foi “descoberta" e assim batizada por Américo Vespúcio em 01 de Novembro de 1501, dia consagrado a todos os santos no calendário da Igreja Católica" (SOUTO, 2004, p.29). Naquele período, "a região do recôncavo baiano, que abraça toda a área da BTS e compreende vários rios e enseadas de portes variados, era coberta por densas florestas e bosques de manguezais" (HATJE; ANDRADE, 2009, p. 19). A BTS sempre foi caracterizada por sua riqueza natural: ilhas, recifes de corais, manguezais, apicuns, uma diversidade de espécies de peixes, mariscos e duas baías menores, Iguape e Aratu. Fato que levou a mesma a ter a sua importância ecológica reconhecida com a "criação da Área de Proteção Ambiental Baía de Todos os Santos, através do Decreto Estadual no. 7595 em 5 de junho de 1999. Com cerca de $800 \mathrm{~km}^{2}$, esta unidade de conservação abrange 54 ilhas [...] com importantes áreas remanescentes de Mata Atlântica e de manguezais" (SOUTO, 2004, p.30).

Tais áreas são consideradas, historicamente, de suma importância para a manutenção das condições naturais da baía, assim como das populações tradicionais que 
residem em seu entorno. Todavia o que se observa é que os ambientes que constituem a BTS têm sido modificados - desde sua "re-descoberta"- gradativamente, com destaque para alguns momentos históricos: i) a implantação da monocultura da cana-de-açúcar e a instalação dos engenhos; ii) a chegada de Tomé de Souza, em 1549, o início da construção da cidade de Salvador e a ocupação das terras no entorno da baía (destaque para as culturas da mandioca e do fumo); iii) em 1950, quando a Petrobras inaugura a refinaria Landulpho Alves (RLAM) em Mataripe, marco inicial do desenvolvimento da indústria petroquímica no estado, consolidada posteriormente com a implantação do complexo petroquímico e o Centro Industrial de Aratu; e iv) a implantação e expansão de inúmeras e diferenciadas atividades na baía (turismo, aquicultura, portos, estaleiros, indústria automobilística, imobiliária etc.) (HATJE; ANDRADE, 2009). Ainda de acordo com os autores, o histórico de ocupação desenvolvido na BTS atribuiu ao local, o titulo de uma das áreas mais antropizadas do estado da Bahia.

O cenário se agrava quando observamos nessa região a presença de inúmeras comunidades tradicionais que sobrevivem diretamente das atividades da pesca e mariscagem, que são desenvolvidas nos múltiplos espaços que compõem a baía. $\mathrm{O}$ processo de ocupação territorial desenvolvido na BTS ocorreu, e ainda ocorre com base na “expulsão/desarticulação” de inúmeras dessas comunidades de seus territórios. É nesse contexto que objetiva-se, no presente artigo, apresentar uma análise das especificidades que envolvem as disputas territoriais presentes nas comunidades tradicionais pesqueiras da Baía de Todos os Santos (BTS) e, a partir disso, os desafios e perspectivas que envolvem a regularização de seus territórios.

Para tal, metodologicamente, buscamos através da realização de levantamentos bibliográficos, estatísticos, cartográficos e da realização de pesquisa de campo, construir um banco de dados que nos permitiu identificar e analisar as principais especificidades que envolvem as comunidades pesqueiras do litoral baiano, em especial da BTS; assim como espacializar através de tabelas e mapas temáticos a distribuição dessas comunidades e as principais disputas territoriais vivenciadas. Tais etapas nos levaram a pensar os desafios e perspectivas que envolvem a regularização dos territórios pesqueiros no litoral baiano. 
As comunidades tradicionais pesqueiras e quilombolas da Baía de Todos os Santos

A pesca artesanal praticada pelas comunidades tradicionais pesqueiras da BTS representa, "sobretudo, uma herança cultural secular, que dá sentido à existência individual, regula a vida em grupo e provê material à imaginação social" (BANDEIRA; BRITO, 2011, p. 304).Em sua maioria trata-se de comunidades que têm, na prática da pesca, uma dupla finalidade: a comercialização e a subsistência como formas de garantir a sua reprodução. Para algumas comunidades, a pesca representa a principal fonte de renda; para outras, a pesca é coexercida com algum emprego, geralmente a agricultura, o comércio, a indústria ou o turismo (MPA, 2010; BAHIA PESCA, 2010). Uma característica importante que envolve essas comunidades refere-se aos laços de identificação e pertencimento desenvolvidos entre as mesmas e os espaços apropriados para a prática de suas atividades. Há acima de tudo o respeito por esses espaços, que constituem o território pesqueiro.

O território dos pescadores artesanais é compreendido aqui enquanto um território articulado, uma vez que este não se restringe ao espaço marítimo (pratica da pesca). Engloba também o espaço terrestre, onde alguns grupos desenvolvem não somente as atividades complementares à pesca, mas principalmente suas "atividades de vida e reprodução social”. O território pesqueiro "envolve áreas de pesca e coleta, as áreas de moradias, os locais de embarque e os trajetos com seus barcos, os locais sagrados e as áreas necessárias à reprodução física e cultural do grupo" (MPP, 2014, p.19). Os pescadores artesanais "não vivem só na água, precisam da terra e da água, tendo nessa interface o mangue e as matas ciliares, a floresta, importantes para a garantia do trabalho tradicional, construção de instrumentos de trabalho, artesanato, espiritualidade, mística e mitos (histórias, crenças, lendas)" (MPP, 2012, p. 6).

Outro ponto de destaque no território das comunidades tradicionais pesqueiras da BTS refere-se à especificidade/complexidade que envolve os espaços ali existentes. Além de integrarem uma Área de Proteção Ambiental, os inúmeros espaços que compõem os territórios pesqueiros da BTS também integram territórios quilombolas ou áreas demarcadas como Reserva Extrativista. É nessa relação com o território que destacamos um cenário existente em inúmeras comunidades pesqueiras do litoral do Estado: muitas comunidades tradicionais pesqueiras também se reconhecem enquanto quilombolas.

Das 900 comunidades quilombolas identificadas, 180 encontram-se localizadas na BTS (GEOGRAFAR, 2018). Trata-se de comunidades quilombolas que têm, desde as 
raízes de sua constituição a prática da pesca e da mariscagem como principal fonte de renda. Sobre essas "múltiplas identidades", é importante destacar a forma com que as relações sociais, econômicas, ambientais e culturais estabelecidas com o território são ainda mais intensas, uma vez que neste articulam-se distintos espaços (marítimos e terrestres), usos, significados e territorialidades. Para essas comunidades, o território é compreendido enquanto espaço de vida e reprodução social, no qual a garantia das condições de acesso, uso e controle é indispensável à própria reprodução da comunidade.

Outra dimensão existente nesse cenário refere-se ao reconhecimento do direito dessas comunidades sobre o seu território. É sabido que existem no país instrumentos jurídicos que reconhecem os direitos das comunidades tradicionais e seus territórios, a exemplo da Constituição Federal de 1988, da Política Nacional de Desenvolvimento Sustentável dos Povos e Comunidades Tradicionais (Decreto, $\mathrm{n}^{\circ}$ 6.040/2007) e da Convenção 169 da Organização Internacional do Trabalho, da qual o Brasil é signatário. Esta última, ao falar sobre "povos indígenas e tribais", considera que a comunidade tradicional possui direitos sobre seus territórios. As comunidades pesqueiras, apesar de se inserirem nas características apresentadas por essa Convenção como comunidades tradicionais, não têm esses direitos reconhecidos. Assim como as definições que existem na Constituição e no Decreto $n^{\circ}$ 6.040/2007 não contemplam as especificidades que envolvem os pescadores artesanais e os seus territórios.

Já as comunidades quilombolas têm assegurado no art. 68 da CF que: "aos remanescentes das comunidades dos quilombos que estejam ocupando suas terras é reconhecida a propriedade definitiva, devendo o Estado emitir-lhes os títulos respectivos" (BRASIL, 1988). O Decreto $\mathrm{n}^{\circ} 4887 / 2003$ considera como remanescentes de quilombolas os "grupos étnico-raciais, segundo critérios de autoatribuição, com trajetória histórica própria, dotados de relações territoriais específicas, com presunção de ancestralidade negra relacionada com a resistência à opressão histórica sofrida” (BRASIL, 2003) e regulamenta "o procedimento para identificação, reconhecimento, delimitação, demarcação e titulação das terras ocupadas por remanescentes das comunidades dos quilombos" (BRASIL, 2003).

As questões apresentadas nos levam a constatar que as comunidades tradicionais pesqueiras e quilombolas da BTS possuem características que lhes atribuem um caráter específico, que demandam ao Estado, nas suas diversas representações, uma rigorosa "gestão, proteção e fiscalização" de seus territórios. No entanto, o que tem se observado 
historicamente é uma massiva ocupação, modificação e destruição dos espaços que compõem esses territórios por atividades industriais, entre outras e, com isso, a expulsão de inúmeras comunidades.

Apesar de esses empreendimentos estarem presentes em quase todas as comunidades pesqueiras do Estado, há alguns pontos de intensa concentração, a exemplo da BTS. Essa Baía tornou-se, historicamente, um dos principais pontos de investimento e concentração das atividades industriais do estado da Bahia. Atividades que têm ocasionado diversas modificações nas condições naturais da Baía e na distribuição de seus ecossistemas. Assim como tem interferido diretamente no desenvolvimento das comunidades pesqueiras locais.

\section{As disputas territoriais presentes na Baía de Todos os Santos}

As contradições que envolvem os territórios pesqueiros da BTS iniciam-se no momento em que há a ocupação de um espaço até então utilizado pelas comunidades tradicionais para a inserção de novas atividades que interferem diretamente no acesso, uso, controle do território pelas comunidades. Daí o surgimento das disputas territoriais.

Conforme apontado anteriormente, a BTS tem sido modificada desde sua "redescoberta" pelos portugueses, com destaque para alguns momentos históricos. "O início da impactação antrópica na Baía de Todos os Santos (BTS) data do século XVI, com a construção da cidade do Salvador, a implantação dos primeiros engenhos de cana-deaçúcar e o princípio da "indústria" de construção naval” (HATJE; ANDRADE, 2009, p.247). Entretanto, “a aceleração do processo de alteração ambiental ocorreu na metade do século XX, quando os municípios localizados no entorno da BTS experimentaram um período de transformação econômica e social, devido à Petrobras ter escolhido a Bacia Sedimentar do Recôncavo para sistematizar suas pesquisas e explorar Petróleo (HATJE; ANDRADE, 2009, p.247).

Na década de 1950, a Petrobras instalou em Mataripe a refinaria Landulpho Alves. “O petróleo - símbolo dessa modernidade, [...] foi o elemento-chave para a implantação de um parque industrial na Bahia e para dinamização da economia da Região Metropolitana de Salvador e seu entorno" (ESCUDERO, 2010, p. 26). Fato que se concretiza com a criação do Centro Industrial de Aratu (CIA), no final da década de 60 e a formação do Complexo Petroquímico de Camaçari na década de 70 (HATJE; 
ANDRADE, 2009). Desde então, mais de 200 indústrias (químicas, metalúrgicas, farmacêutica e alimentícias) se instalaram no CIA.

A implantação dessas indústrias na BTS ocasionou e intensificou "direta/indiretamente" um contínuo processo de inserção e expansão de novas e diferenciadas atividades na Baía: turismo, aquicultura, portos, estaleiros, indústria imobiliária etc. Tal processo aliado a uma conjuntura política estadual de constantes incentivos à industrialização, em especial na zona costeira, levou a BTS a ser considerada das grandes áreas antropizadas do estado da Bahia.

$\mathrm{Na}$ medida em que novas atividades industriais foram inseridas na BTS, inúmeras mudanças significativas também ocorreram na mesma, seja nas condições ambientais na baía, seja na ocupação dos espaços utilizados pelas comunidades tradicionais ali existentes. Os espaços que eram de uso das comunidades aos poucos foram sendo ocupados, delimitados e controlados pelas indústrias. As condições naturais da baía foram modificadas, espécies foram reduzidas, coroas e manguezais destruídos/desmatados, caminhos tradicionais foram interrompidos, áreas de pesca, mariscagem, agricultura e extrativismo foram cercadas e tiveram seu acesso proibido, tubulações e poços de petróleo e gás foram inseridos na comunidade etc. Situações frequentemente vivenciadas pelas comunidades pesqueiras e, que têm sido o principal motivo de inúmeras disputas territoriais e conflitos.

A inserção dessas atividades na Baía, quando não ocasiona a "restrição/perda" imediata das áreas de uso dos pescadores artesanais, tem obrigado várias comunidades a “dividir" seus espaços com empreendimentos de diversos segmentos, a exemplo:

i) Turístico: Este segmento tem cercado e desmatado diversas espaços para construção de hotéis e pousadas, a destacar nos últimos anos a ocupação, desmatamento e privatização de coroas e ilhotes na BTS. Por exemplo, as comunidades pesqueiras no município de Santo Amaro, Saubara e São Francisco do Conde, desde 2011, têm enfrentado constantes disputas territoriais com empresários que tentam privatizar a Ilha de Cajaíba, alguns ilhotes e coroas das proximidades, para a construção de hotéis e resorts.

ii) Portuário: A ampliação e criação de novos portos e estaleiros consistem num dos grandes conflitos que envolvem as comunidades tradicionais pesqueiras da BTS. Atualmente, a BTS abriga além dos portos de Salvador e Aratu, diversos terminais marítimos: (i) Terminal da Dow Quimica; (ii) o Terminal da Gerdau/Usiba; (iii) o Terminal Dias Branco; (iv) o Terminal da Ford; (v) o Terminal São Roque; (vi) os 
terminais de passageiros de São Joaquim e Bom Despacho e (vii) a Base Naval de Aratu (HATJE; ANDRADE, 2009).

Os portos de Salvador e Aratu, assim como os demais terminais marítimos, podem ser considerados como "fontes de contaminação por hidrocarbonetos, metais e demais produtos transportados pela região [...] o porto de Salvador movimenta mais de $400.000 \mathrm{t}$ ano de produtos químicos e fertilizantes, enquanto Aratu [...] cerca de 4 milhões de t ano" (HATJE; ANDRADE, 2009, p.250). Na BTS, já aconteceram diversos derramamentos de produtos químicos e óleo, a destacar o derramamento de 48.000 litros de petróleo bruto em 1992; em abril de 2009, o vazamento de cerca de 2.500 litros de óleo e, recentemente, em 2013, quando um incêndio atingiu um navio carregado de gás propeno no Porto de Aratu e cerca de 500 mil litros de combustível se espalharam na BTS. Tais vazamentos "podem ter impacto negativo significativo na biota, nas áreas de manguezais, e implicações diretas nas comunidades que tem no extrativismo a principal fonte de proteína e renda" (HATJE; ANDRADE, 2009, p.251).

iii) Petroquímico: A inserção da indústria petroquímica da BTS tem ocasionado, além da privatização de áreas de uso das comunidades para a inserção de poços de petróleo e gás, a contaminação das águas, do ar, mariscos, pescados e dos próprios moradores das comunidades. Por exemplo, a Companhia Química do Recôncavo (CQR), que operou nas margens da Baía de Itapagipe, onde atualmente funciona o Polo Petroquímico, também é considerada uma das grandes contaminadoras da região. "Estima-se que a planta de cloro-álcali desta indústria despejou entre 2 e 4 kg diários de cloreto de mercúrio nas águas de Itapagipe, durante seus doze anos de operação" (HATJE; ANDRADE, 2009, p.250).

iv) Automobilístico: Desde o ano de 2005, também compõe o sistema portuário da BTS o terminal privativo da Ford. De acordo com as comunidades residentes nos municípios que integram o setor de pesca da BTS, a instalação desse terminal ocorreu numa área de intenso uso dos pescadores artesanais, haja vista a diversidade de peixes e mariscos existentes na região. Com sua instalação, além da restrição de acesso às coroas e pontos de pesca, o transporte de navios para escoamento dos carros interfere e coloca em risco a vida de diversos pescadores que atuam na região, impactando diretamente no desenvolvimento de suas atividades 
Territórios pesqueiros na Baía de todos os Santos:

Kássia Aguiar Norberto Rios disputas, desafios e perspectivas de sua regularização

Na Figura 01, podemos observar que a maioria destes empreendimentos encontrase inserida diretamente nas áreas de uso das comunidades, ou seja, nos territórios pesqueiros.

Figura 1. Principais disputas territoriais identificadas nas comunidades tradicionais pesqueiras e quilombolas da BTS, 2016.

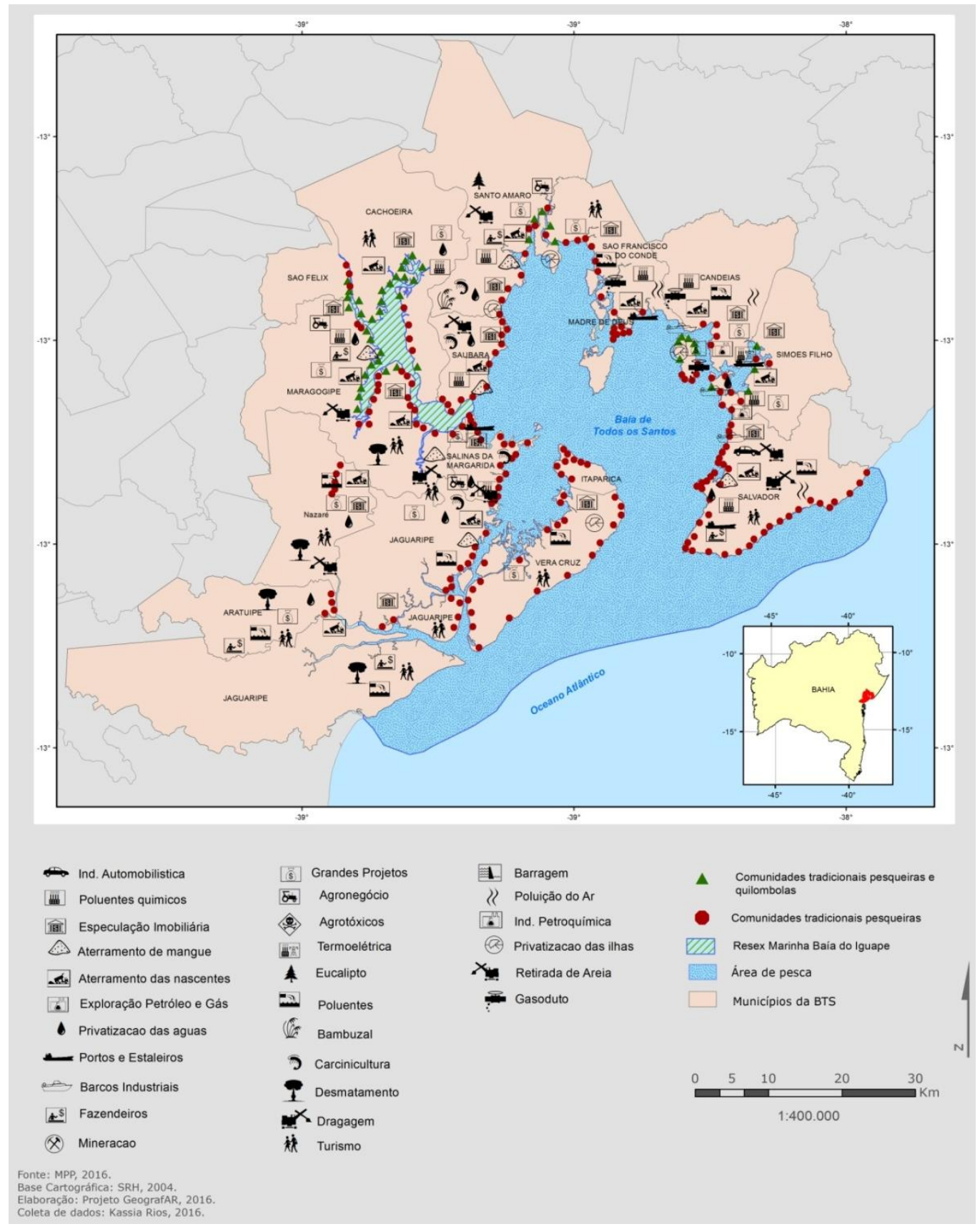

As comunidades pesqueiras da BTS relatam ainda a existência de conflitos com o setor imobiliário, pois com a inserção das indústrias há uma maior demanda residencial e 
conflitos fundiários, nos quais diversas comunidades relatam a constante ocupação e privatização de parte de seus territórios por fazendeiros e com isso a restrição/proibição de acesso aos caminhos que levam às áreas de pesca e mariscagem. A perda de espaços que constituem os territórios pesqueiros para plantações de eucalipto e bambuzal também faz parte das diversas disputas territoriais existentes na BTS. Nos últimos anos, também foi construída uma termoelétrica, porém, ainda não está em funcionamento.

Em pesquisa realizada em jornais do estado e sites de notícias locais e alguns, nacionais, durante o período de 2000 a 2015, constatamos que semanalmente há pelo menos uma notícia sobre as disputas territoriais que envolvem as comunidades pesqueiras da Bahia, em especial da BTS. A seguir, apresentamos duas das principais notícias que se repetem frequentemente nos jornais locais, envolvendo disputas territoriais com comunidades pesqueiras da BTS: i) Poluição marítima dizima pescados na BTS e dificulta sobrevivência das comunidades pesqueiras, e ii) Poluição na BTS causa problemas aos moradores: diagnóstico revela que em níveis altos, o chumbo causa anemia e afeta a evolução física e cognitiva das crianças.

Se observarmos o quantitativo de impactos socioambientais que as empresas atuantes na BTS ocasionaram/ocasionam na Baía e nas comunidades ali existentes, notaremos que se trata de um processo histórico invisibilizado frente ao Estado e órgãos ambientais. Pois, mesmo com a existência de diversos estudos e pesquisas demonstrando as consequências desses impactos à baía e às comunidades pesqueiras, as empresas que já estão instaladas continuam a desenvolver suas atividades regularmente - algumas ampliando suas áreas -, assim como novas empresas têm ocupado outros espaços no entorno da baía.

Inúmeras pesquisas para monitoramento da poluição do ar, das águas, dos pescados e da saúde dos moradores das comunidades já foram realizadas na BTS. Muitas atestam a contaminação por poluentes químicos e suas possíveis consequências ao meio ambiente e às comunidades. Todavia, não há por parte do Estado e órgãos ambientais um controle e fiscalização intensivos para combater a emissão de tais poluentes. Em alguns casos, quando as comunidades realizam manifestações e ocupações reivindicando das empresas, estado e órgãos ambientais uma fiscalização imediata, são feitos "acordos de uso da baía e promessas de novas fiscalizações". Entretanto, na prática a maioria dessas ações não acontece. 
Observa-se que não há uma fiscalização/aplicação do marco legal que rege a instalação e o funcionamento desses empreendimentos, a exemplo do cenário exposto na BTS. Nesse contexto dois questionamentos emergem: A BTS integra uma APA, possui uma Resex e é o território de inúmeras comunidades pesqueiras e quilombolas. Esse cenário não deveria garantir a preservação da Baía e as comunidades envolvidas, alguns direitos sobre seu território? A legislação atual brasileira abrange as especificidades existentes nos territórios pesqueiros? Há algum instrumento legal que garanta os direitos territoriais das comunidades pesqueiras?

Tais respostas nos levam a alguns dos grandes desafios que envolvem a regularização dos territórios tradicionais da BTS, que por sua vez iniciam quando observamos o cenário ao qualas comunidades tradicionais pesqueiras do Brasil foram submetidas historicamente: de exclusão, negação de direitos e invisibilidade. Não há, no país, o reconhecimento - por parte do Estado e dos próprios órgãos gestores - da importância socioeconômica, cultural e ambiental dessas comunidades e, por sua vez, dos espaços historicamente apropriados (território pesqueiro). Historicamente, o Estado tem visto os pescadores artesanais somente como uma categoria de trabalhadores, descartando toda a riqueza social, cultural e ambiental que envolve a tradicionalidade e o modo de vida dessas comunidades.

Na Baía de Todos os Santos existem mais 300 empreendimentos de propriedade do estado e/ou grupos privados (nacionais e internacionais). Trata-se de portos, estaleiros e indústrias de variados segmentos que contribuem significantemente para a economia do estado (IBGE, 2010). Isso significa dizer que a regularização de um território tradicional na região BTS certamente enfrentará grandes desafios, pois envolverá grupos, interesses e poderes de distintas escalas (comunidades, fazendeiros, empresas nacionais, internacionais, Estado etc.).

Os territórios pesqueiros se tornaram, ao longo dos anos, espaços de interesse estratégico ao desenvolvimento do capital e, através do apoio do Estado, têm sido massivamente ocupados por empreendimentos industriais dos diversos segmentos. Portanto, uma das questões que não podemos desconsiderar na discussão dos territórios tradicionais da BTS refere-se à realidade que envolve tais espaços e o papel do Estado. 


\section{Considerações finais}

Os desafios existentes no processo de regularização dos territórios pesqueiros da BTS iniciam quando observamos o cenário de invisibilidade, exclusão e negação de direitos ao qual as comunidades tradicionais locais têm sido submetidas historicamente. Não há no país o reconhecimento pelo Estado, e pelos próprios órgãos gestores do setor pesqueiro, da importância social, econômica, cultural e ambiental dessas comunidades.

Mesmo se tratando de territórios legais, tais como Áreas de Proteção Ambiental (APA), Reservas Extrativistas e/ou territórios quilombolas etc., observa-se que os espaços de uso das comunidades se tornaram áreas de interesse estratégico ao desenvolvimento do capital. Isso tem implicado aos pescadores(as) artesanais uma necessidade cotidiana: a luta pela efetivação de seus direitos e, principalmente, pela permanência nos territórios pesqueiros. Tais fatos, aliados a uma conjuntura política de constante incentivo à expansão industrial no país nos diversos setores (aquicultura, portuário, turístico, petroquímico, metalúrgico etc.), e em especial nas zonas costeiras, têm feito com que as políticas públicas busquem privilegiar os grandes empreendimentos que têm sido inseridos nos territórios pesqueiros.

\section{REFERÊNCIAS}

BAHIA PESCA. Dados da atividade pesqueira no estado da Bahia. Salvador: BP, 2010.

BANDEIRA, Fabio P. S. de; BRITO, Ronan R. C. de. Comunidades pesqueiras na Baía de Todos os Santos: aspectos históricos e etnoecológicos. In: CAROSO, Carlos etal. Baía de Todos os Santos: aspectos humanos / Salvador: EDUFBA, 2011. 600 p.

BRASIL. Decreto $\mathbf{n}^{\mathbf{0}} \mathbf{4 . 8 8 7}$, de 20 de novembro de 2003. Regulamenta o procedimento para identificação, reconhecimento, delimitação, demarcação e titulação das terras ocupadas por remanescentes das comunidades dos quilombos de que trata o art. 68 do Ato das Disposições Constitucionais Transitórias. Brasília, DF, 20 nov. 2003.

BRASIL. Constituição (1988). Constituição da República Federativa do Brasil. Brasília, DF: Senado Federal: Centro Gráfico, 1988.

ESCUDERO, Silvia. Urbanização (In) sustentável em Ilha de Maré: Estudo de caso da vila de Santana. 2010. 85f. Monografia (Especialização)-UCSAL, Salvador, Bahia, 2010 . 
GEOGRAFAR - A Geografia dos Assentamentos na Área Rural. Banco de Dados 2016. Grupo de Pesquisa do Programa de Pós-Graduação em Geografia. Salvador: UFBA/CNPq, 2018.

HATJE, V; ANDRADE, J. Baía de Todos os Santos: aspectos oceanográficos. Salvador: EDUFBA, 2009. 306p.

IBGE. Instituto Brasileiro de Geografia e Estatística. Censo demográfico 2010. Disponível em: <http://www.censo2010.ibge.gov.br> acesso em: 01 jun. 2016.

MPA, Ministério da Pesca e Aquicultura. Boletim Estatístico da Pesca e Aqüicultura - 2008 e 2009. MPA, 2010.

MPP. Movimentos dos Pescadores e Pescadoras Artesanais. Cartilha - Projeto de Lei de Iniciativa Popular Sobre o Território Pesqueiro.MPP, 2014.

MPP. Movimentos dos Pescadores e Pescadoras Artesanais. Identidade e Território das Comunidades Tradicionais Pesqueiras. In:MPP. Cartilha - Trabalho de Base da Campanha Pelo Território Pesqueiro.MPP. Pernambuco, 2012.

SOARES, Lucy S. H. et al. Pesca e Produção Pesqueira. In: HATJE, V; ANDRADE, J. Baía de Todos os Santos: aspectos oceanográficos. Salvador: EDUFBA, 2009.

SOUTO, F. J. B. A ciência que veio da lama:uma abordagem etnoecológica abrangente das relações ser humano/manguezal na comunidade pesqueira de Acupe, Santo Amaro, Bahia. 2004. 319f. Tese (Pós-Graduação Ecologia e Recursos Naturais) UFSCAR, São Paulo, 2004.

Recebido em 29/03/2020.

Aceito para publicação em 24/07/2020. 